Original Research Article

\title{
Comparison of effects of benidipine and amlodipine on clinical and biochemical parameters in hypertensive patients: an observational study
}

\author{
S. V. Dange ${ }^{1}$, Bhagyashree Sharma ${ }^{2 *}$, Pallav P. Kataria ${ }^{2}$, Ritika Vaid ${ }^{2}$
}

\begin{abstract}
${ }^{1}$ Medical Director, Dhanashree Hospital, Samarth Nagar, New Sangvi, Pune, Maharashtra, India

${ }^{2}$ Department of Pharmacology, Dr. D. Y. Patil Medical College, Pimpri, Pune, Maharashtra, India
\end{abstract}

Received: 03 July 2017 Accepted: 28 July 2017

\section{*Correspondence to: Dr. Bhagyashree Sharma, Email: dr.bhagyashree.sharma@ gmail.com}

Copyright: () the author(s), publisher and licensee Medip Academy. This is an openaccess article distributed under the terms of the Creative Commons Attribution NonCommercial License, which permits unrestricted noncommercial use, distribution, and reproduction in any medium, provided the original work is properly cited.

\begin{abstract}
Background: Hypertension is a widespread public health problem and a major risk factor for cardiovascular disease. Amlodipine, a calcium channel blocker, dilates arterioles by blocking L-type calcium channels. Benidipine inhibits L, N, and $\mathrm{T}$ type calcium channels. We compared the efficacy of Amlodipine and benidipine on blood pressure, pulse rate, proteinuria and lipid profile in hypertensive patients.

Methods: The study was an observational, prospective, open label comparison. Eligible hypertensives were given either amlodipine $(5 \mathrm{mg} / \mathrm{d})$ or benidipine (4mg/d). Clinical features and laboratory parameters were recorded initially and after 3 months. Adverse events were recorded with the help of a questionnaire. Compliance was assessed by return pill count.

Results: Out of 35 patients, recruited for study, 16 received amlodipine and 17 were treated with benidipine and two were lost during follow up. Both the groups were well matched in terms of age, body weight, clinical findings and laboratory values. Both the drugs significantly $(\mathrm{P}<0.05)$ reduced systolic $(142 \pm 16$ to $138 \pm 15$ vs. $148 \pm 16$ to $134 \pm 14 \mathrm{mmHg}$ ) and diastolic blood pressure ( $81 \pm 9$ to $79 \pm 7$ ). In the Amlodipine group the pulse rate after treatment tended to be higher than before $(70 \pm 9$ to $72 \pm 10 \mathrm{bpm})$. In the Benidipine group there was decrease in pulse-rate after treatment $(69 \pm 9$ to $67 \pm 9)$. Unlike Amlodipine, Benidipine significantly $(\mathrm{P}<0.05)$ decreased urinary protein excretion $(1.0 \pm 1.2$ to $1.1 \pm 1.4$ vs. $1.4 \pm 2.5$ to $1.1 \pm 1.7 \mathrm{~g} / \mathrm{g}-\mathrm{Cr})$ and serum triglycerides $(125 \pm 25$ to $120 \pm 23$ vs $130 \pm 26$ to $115 \pm 21 \mathrm{mg} / \mathrm{dl})$.

Conclusions: In this study, amlodipine and benidipine were found to be be equally effective anti-hypertensive in patients with stage 1 hypertension. However, there was significant reduction in proteinuria and serum triglycerides in Benidipine group as compared to Amlodipine group. Benidipine may be a better alternative to existing calcium channel blockers.
\end{abstract}

Keywords: Amlodipine, Benidipine, Hypertension

\section{INTRODUCTION}

Hypertension is the most common cardiovascular disease. In India, $29.8 \%$ population are suffering from hypertension. ${ }^{1}$ According to the European Society of Hypertension-European Society of Cardiology guidelines, all major classes of antihypertensive (Diuretics, $\beta$ - blockers, CCBs, ACEIs, ARBs) are suitable for initial and maintenance therapy, either alone or in combination. High-risk conditions benefited by the use of CCBs include coronary artery disease and diabetes (particularly in combination with other agents). In addition, CCBs may be particularly useful in elderly, isolated systolic hypertension, angina pectoris, peripheral vascular disease, carotid atherosclerosis, pregnancy and Raynaud's 
syndrome. $^{2}$ Recently, in eighth JNC report, CCBs have shown good results over ACEI in the black population suffering from hypertension in terms of efficacy and prevention of stroke. ${ }^{3}$ Calcium antagonists are now widely used for the treatment of various types of hypertension. The most frequently used calcium channel blocker (CCB) in India is amlodipine. Amlodipine belongs to the L-type calcium channel blockers, and has a potent blood pressure lowering effect and few adverse effects like pedal edema and tachycardia. Recently, a new calcium-channel blocker-benidipine-has become available in Indian market. It is a triple L, N, T-calcium channel blocker with promising end organ protection effects. Hence, this observational study was designed to compare the effects of benidipine with those of amlodipine in patients of essential hypertension.

\section{METHODS}

\section{Study design}

This was a 3 months prospective, observational study conducted at Dhanashree Hospital, New Sangavi, Pune411027 between December 2015 to May 2016. Approval of the Institutional Ethics Committee and patient consent were obtained prior to the study.

\section{Inclusion criteria}

Newly diagnosed patients of essential hypertension-stage 1 (BP 140-160/ 90-100mm Hg) of either gender in the age group of 35-75 years, attending outpatient department of Dhanashree Hospital.

\section{Exclusion criteria}

- $\quad$ Patients with preexisting renal, hepatic or cardiac disease

- $\quad$ Patients with pedal edema, hypoproteinemia, anemia

- Pregnant women

- Patients taking drugs such as non-steroidal antiinflammatory drugs.

\section{Study procedure}

After initial screening, demographic data, past medical history, family history, and findings of clinical examination were recorded in the case report form. Patients were treated with either amlodipine $5 \mathrm{mg} / \mathrm{d}$ or benidipine $4 \mathrm{mg} / \mathrm{d}$ after dinner for three months. The patients were examined by the consultant physician and blood pressure was measured in right arm, sitting posture by the auscultatory method using standard mercury sphygmomanometer. Two recordings of blood pressure were taken at an interval of 15-20min. The BP was measured at monthly intervals and target BP was defined as $130 / 85 \mathrm{~mm} \mathrm{Hg}$.

Patients were followed up every month during the trial. Pedal edema was assessed by clinical method over the medial malleolus of both legs. Presence of pedal edema on either of the legs was considered as positive for the pedal edema. Patient compliance was assessed by pill count method on every visit. Patients were followed every month, screened for pedal edema, other adverse events and blood pressure control. Patients were instructed to consult the physician immediately in case of any unusual side effects (including pedal edema) if it occurred before the follow-up date. Serum lipids and urinary protein were estimated at base line and after 3 months. Urinary protein content was standardized for urinary excretion of $1 \mathrm{~g}$ creatinine. The ACR was measured using the immunoturbidimetry method.

Normoalbuminuria, microalbuminuria, and overt proteinuria were defined as an ACR of 10-30, 30-300, and over $300 \mathrm{mg} / \mathrm{g}$, respectively. Urinary albumin excretion:creatinine ratio was measured by latex agglutination assay using a spot urine sample. Serum concentration of total cholesterol, HDL-C, LDL-C and TG were determined by the enzymatic methods with an autoanalyzer. All DM patients in this study were diagnosed as type 2. Dyslipidemia was defined on the basis of abnormal lipid level [LDL-Cholesterol (LDL-C) $\geq 140 \mathrm{mg} / \mathrm{dl}$, HDL-Cholesterol (HDL-C) <40mg/dl, Triglyceride $(\mathrm{TG}) \geq 150 \mathrm{mg} / \mathrm{dl}]$.

\section{Statistical analysis}

Values are expressed as the mean $\pm \mathrm{SD}$. The difference of the baseline characteristics and change in BP and PR parameter between the Amlodipine and benidipine groups were compared using an unpaired t-test. The difference between the values before and after antihypertensive medication within the same group were tested using a paired t-test. The differences in the incidence of pedal edema between benidipine and amlodipine groups were compared by Fisher's exact test. $\mathrm{P}$ value $<0.05$ considered statistically significant.

\section{RESULTS}

Table 1: Baseline clinical features of patients.

\begin{tabular}{|lll|}
\hline Sex (M:F) & $\begin{array}{l}\text { Amlodipine } \\
(\mathbf{N}=16)\end{array}$ & $\begin{array}{l}\text { Benidipine } \\
(\mathbf{N}=17)\end{array}$ \\
\hline Age (yrs) & $10: 6$ & $12: 5$ \\
\hline BMI (Kg/m $)$ & $62 \pm 5.3$ & $60 \pm 4.1$ \\
\hline T2 DM (n) & $25.1 \pm 3.4$ & $24.0 \pm 2.6$ \\
\hline Systolic BP (mm Hg) & 5 & 4 \\
\hline Diastolic BP (mm Hg) & $142 \pm 16$ & $148 \pm 16$ \\
\hline Pulse Rate (bpm) & $70 \pm 9$ & $95 \pm 6$ \\
\hline Pedal edema & Nil & $69 \pm 9$ \\
\hline
\end{tabular}

Figures are Mean $\pm \mathrm{SD}$, no significant difference between the groups at base-line

Seventy one patients of essential hypertension were screened. Out of these, 41 patients had stage 1 
hypertension and were eligible for recruitment in the study. However, six patients did not sign the consent. Remaining thirty five patients were included in the study. Two patients dropped out during the follow up. Sixteen patients received amlodipine, whereas 17 patients were treated with benidipine. Their clinical features are shown in Table 1.

Table 2 shows the results of biochemical parameters at base-line.

Table 2: Baseline biochemical features of patients.

\begin{tabular}{|ll|l|}
\hline & $\begin{array}{l}\text { Amlodipine } \\
(\mathbf{N}=16)\end{array}$ & $\begin{array}{l}\text { Benidipine } \\
(\mathbf{N}=17)\end{array}$ \\
\hline Proteinuria (n) & 8 & 7 \\
\hline $\begin{array}{l}\text { Urinary microalbumin } \\
(\mathrm{mg} / \mathrm{L})\end{array}$ & $88 \pm 27$ & $81 \pm 25$ \\
\hline Serum creatinine (mg/dl) & $0.8 \pm 0.3$ & $0.7 \pm 0.2$ \\
\hline Serum ALT & & \\
\hline TC (mg/dl) & $207 \pm 43$ & $202 \pm 34$ \\
\hline TG (mg/dl) & $125 \pm 25$ & $130 \pm 26$ \\
\hline HDL-c (mg/dl) & $42 \pm 12$ & $46 \pm 11$ \\
\hline LDL-c (mg/dl) & $125 \pm 25$ & $134 \pm 28$ \\
\hline HbA1c (\%)* & $7.6 \pm 1.5$ & $7.7 \pm 1.7$ \\
\hline
\end{tabular}

Figures are Mean $\pm S D$, no significant difference between the groups, *-only for diabetics

Table 3 shows the results after the treatment with either amlodipine or benidipine.

Table 3: Effect of amlodipine and benedipine on various parameters.

\begin{tabular}{|lll|}
\hline Parameter & $\begin{array}{l}\text { Amlodipine } \\
\text { N=16 }\end{array}$ & $\begin{array}{l}\text { Benidipine } \\
\mathbf{N}=17\end{array}$ \\
\hline Systolic BP (mmHg) & $138 \pm 15^{*}$ & $134 \pm 14^{*}$ \\
\hline Diastolic BP (mmHg) & $81 \pm 9^{*}$ & $79 \pm 7^{*}$ \\
\hline Pulse rate (bpm) & $72 \pm 10$ & $67 \pm 9^{* \wedge}$ \\
\hline Serum TG (mg/dl) & $120 \pm 23$ & $115 \pm 21^{*}$ \\
\hline $\begin{array}{l}\text { Urinary microalbumin } \\
\text { (mg/L) }\end{array}$ & $81 \pm 23$ & $52 \pm 16^{*}$ \\
\hline
\end{tabular}

$* \mathrm{P}<0.05$ Comparison with base-line

$\wedge \mathrm{P}<0.05$ Comparison between the groups

Both drugs effectively and significantly $(\mathrm{P}<0.05)$ reduced SBP and DBP from base-line levels. There was no significant difference between the two treatments as far as reduction in blood pressure was concerned. However, there was significant decrease in pulse rate with benidipine treatment as compared to that with amlodipine.

Pedal edema was seen in five patients in amlodipine group, while none of the patients from benidipine group had pedal edema. There was significant $(\mathrm{P}<0.05)$ reduction in serum triglyceride and urinary microalbumin levels, from baseline in the benidipine group. There was no such difference in the amlodipine group. Results with other lipid parameters were not statistically significant.

\section{DISCUSSION}

We found in this small study that both amlodipine $(5 \mathrm{mg} / \mathrm{d})$ and benidipine $(4 \mathrm{mg} / \mathrm{d})$ were equally effective in reducing the SBP and DBP in hypertensive patients. However, there was significant decrease in pulse rate and less incidence of pedal edema in benidipine treated patients. Similarly, the serum triglyceride levels decreased and urinary microalbumin excretion also decreased significantly in benidipine group. Anan et al, compared the antihypertensive effects of benidipine and amlodipine. In their study, benidipine (4-8mg/d) was given to 15 hypertensive patients and amlodipine $(2.5-5 \mathrm{mg})$ was administered in 14 patients. Both drugs were effective as anti-hypertensives.

Benidipine, is a new calcium blocker, which blocks all L, $\mathrm{N}$ and $\mathrm{T}$ channels. Its action bradycardia observed in the study. Cilnidipine, another calcium blocker, acting on $\mathrm{N}$ channels, has also been reported to reduce excessive release of catecholamine and suppress the reflex tachycardia compared with amlodipine in hypertensive patients. $^{4}$

Benidipine causes less activation of sympathetic nerve activity by hypotensive baroreflex as compared to other CCBs. ${ }^{5}$

Blood pressure control is important in suppressing the onset of renal dysfunction. Cilnidipine has been reported to reduce glomerular pressure ${ }^{6}$ Kojima et al, compared the effects of amlodipine and cilnidipine on urinary protein excretion. They reported that the level of urinary protein elevated after Amlodipine treatment in urinary protein positive hypertensive patients as compared to baseline level, while there was no significant difference in the level of urinary protein before and after Cilnidipine treatment. ${ }^{7}$ We have also observed reduction in micoalbuminuria in this study. Ohishi et al, studied the effects on BP and proteinuria after changeover from amlodipine to benidipine in hypertensive patients. They observed that in 58 patients by switching to benidipine, more than $40 \%$ achieved optimal BP and significant reduction in proteinuria. ${ }^{8}$ This might be due to dilation of both afferent and efferent arterioles caused by benidipine in contrast to preferential dilation of afferent arterioles by traditional CCBs like amlodipine. ${ }^{9}$ L type calcium channels are present primarily on afferent arterioles, the inhibition of these channels causes dilatation of only afferent arterioles, resulting in elevation of glomerular pressure. On the other hand, $\mathrm{N}$ - type calcium channels, which are located in sympathetic nerve endings, control both afferent and efferent arterioles, thus resulting in well-balanced dilatation of both arterioles.

Concerning lipid metabolism, Cilnidipine has been reported to reduce $\mathrm{TG}$ in hypertensive patients with diabetes mellitus. ${ }^{10}$ Effect of benidipine on serum triglycerides seen in this study is similar. 
There are certain limitations of our study: single centre, single dose, non-blinded, small sample size, short duration.

Further studies are necessary to confirm the results of this study.

\section{CONCLUSION}

A small observational study was conducted to compare the effects of amlodipine and benidipine on BP, serum lipids and proteinuria in hypertensive patients. Both drugs effectively lowered the SBP and DBP. However, benidipine treated group had significantly less tachycardia and less pedal edema. In addition there was significant reduction in microalbuminuria and in serum triglycerides with benidipine treatment. Both treatments were tolerated. Further large scale studies are necessary to confirm these preliminary findings.

\section{ACKNOWLEDGEMENTS}

Authors would like to thank to Koye Pharmaceuticals Pvt. Ltd. Mumbai for free supply of benidipine for the study.

Funding: No funding sources

Conflict of interest: None declared

Ethical approval: The study was approved by the Institutional Ethics Committee

\section{REFERENCES}

1. Anchala R, Kannuri NK, Pant H, Khan H, Franco OH, Di Angelantonio E, et al. Hypertension in India: A systematic review and meta-analysis of prevalence, awareness, and control of hypertension. J Hypertens. 2014;32:1170-7.

2. Basile J. The role of existing and newer calcium channel blockers in the treatment of hypertension. $\mathrm{J}$ Clin Hypertens (Greenwich). 2004;6:621-9.

3. James PA, Oparil S, Carter BL, Cushman WC, Dennison-Himmelfarb C, Handler J, et al. Evidence- based guideline for the management of high blood pressure in adults: Report from the panel members appointed to the Eighth Joint National Committee (JNC 8) JAMA. 2014;311:507-20.

4. Sakata K, Shirotani M, Yoshida H, Nawada R, Obayashi K, Togi K, et al. Effects of amlodipine and cilnidipine on cardiac sympathetic nervous system and neurohormonal status in essential hypertension. Hypertension. 1999 Jun 1;33(6):1447-52.

5. Diabetology K. Benipack [Product Monograph]. Mumbai: Koye Diabetology; 2016.

6. Zhou X, Ono H, Ono Y, Frohlich ED. N-and L-type calcium channel antagonist improve glomerular dynamics, reverse severe nephrosclerosis and inhibits apoptosis and proliferation in an L-NAME/SHR model. J Hypertens. 2002;20:993-1000.

7. Kojima S, Shida M, Yokoyana H. Comparison between Cilnidipine and Amlodipine besilate with respect to proteinuria in hypertensive patients with renal diseases. Hypertens Res. 2004;27:379-85.

8. Ohishi M, Takagi T, Ito N, Terai M, Tatara Y, Hayashi $\mathrm{N}$, et al. Renal-protective effect of T-and L-type calcium channel blockers in hypertensive patients: an Amlodipine-to-Benidipine Changeover (ABC) study. Hypertension Research. 2007 Sep 1;30(9):797-806.

9. Homma K. Renal microcirculation and calcium channel subtypes. Current Hypertension Reviews. 2013;9:182-6.

10. Masuda T, Ogura MN, Moriya T, Takahira N, Matsumoto T, Kutsuna T, et al. Beneficial Effects of L-and N-type Calcium Channel Blocker on Glucose and Lipid Metabolism and Renal Function in Patients with Hypertension and Type II Diabetes Mellitus. Cardiovascular therapeutics. 2011 Feb 1;29(1):46-53.

Cite this article as: Dange SV, Sharma B, Kataria PP, Vaid R. Comparison of effects of benidipine and amlodipine on clinical and biochemical parameters in hypertensive patients: an observational study. Int J Basic Clin Pharmacol 2017;6:2233-6. 